\title{
EFFECT OF EDUCATION ON STIGMA AND DISCRIMINATION TOWARDS MENTAL ILLNESS: A MULTIVARIATE ANALYSIS OF COVARIANCE
}

\author{
Mariana Tumin, Md Mizanur Rahman and Zulkifli Jantan \\ Department of Medical and Community Health Sciences, Universiti Malaysia Sarawak \\ Corresponding author: Md Mizanur Rahman \\ Email: rmmizanur@unimas.my
}

\begin{abstract}
People with mental illness often encounter stigma and discrimination. Mental illness-related stigma and discrimination represent the enormous obstacles that stand in the way of delivering mental health care. Little is known about stigma and discrimination toward mental illness in rural Sarawak. Thus, this study aimed to identify the stigma and discrimination towards mental illness among Sarawak's rural community and factors affecting them. A cross-sectional survey was carried out on 840 respondent adults aged 21 and above. A validated Community Attitude towards Mental Illness (CAMI) and Discrimination towards Mental Illness questionnaire was used for data collection. A Two-way Multiple Analysis of Covariance (Two-way MANCOVA) test was carried out to determine how much gender and education level influence stigma and discrimination towards mentally ill patients. Analysis showed that there was a statistically significant difference of standardised stigma and discrimination scores with education level $(p<.001)$, but not with gender ( $p>.05)$. Age had a positive linear effect on both stigma and discrimination, whereas experience with mentally ill patients negatively affected both stigma and discrimination. Individuals with a lower level of education, older in age, and lesser experience in dealing with the mentally ill would have a higher level of stigma and discrimination towards mental illness. Thus, targeted and practical strategies need to be organised and implemented to combat mental illness-related stigma and discrimination.
\end{abstract}

Keywords: Mental illness, stigma, discrimination, education, rural Sarawak

\section{INTRODUCTION}

Mental illness is one of the non-communicable diseases (NCD) that had substantial public health concern globally. Based on the epidemiological transition theory, the shift has occurred from communicable diseases to non-communicable diseases (NCD) in most countries and established a devastating global premature mortality ${ }^{1,2}$. The disease epidemiology transition is mostly expected to happen in developing countries compared to underdeveloped and developed countries. This is most probably due to the increasing lifespan and rapid ageing processes. Rehm and Shield ${ }^{3}$ reported that the global burden of mental illness accounts for $19 \%$ of years lived with disability (YLDs) and 7\% of disability-adjusted life-years (DALYs). The most type of mental illness associated with high DALYs was depression, with higher rates among women, whereas the men had higher rates among those with substance use disorders ${ }^{3,4}$.

In Malaysia, the National Health and Morbidity Survey (NHMS) is an established platform to monitor the population health status. This survey showed a relative increase in mental illness prevalence from $10.7 \%$ in 1966 to $29.2 \%$ in 2015 among adults ${ }^{5}$. Female respondents demonstrated a slightly higher prevalence of mental illness compared to male respondents. However, it was not significant. NHMS 2019 had assessed the specific mental illness among adults, which was depression and revealed that the prevalence was
$2.3 \%$. However, this prevalence showed a difference compared to an earlier study that estimated the prevalence of depression in Malaysia was between $8 \%$ and $12 \%{ }^{7}$. The prevalence of mental illness for children between 5 to 15 years decreased from $12.1 \%$ in 2015 to $7.9 \%$ in $2019^{6}$. Boys, younger age groups, and rural areas are the risk factors of mental illness among children.

Mental illness is always associated with stigma and discrimination among the public. Stigma is when someone sees a person with mental illness negatively because of his/her mental illness. Similarly, discrimination is when someone treats a person with mental illness negatively because of his/her mental illness. Social stigma and discrimination can worsen mental health problems and stop a person with mental illness from getting the help they need. It would influence them in self-identifying their mental health status and behaviour on seeking a treatment, which led to untreated mentally ill patients ${ }^{8}$. Seeman et al. ${ }^{9}$ conducted a worldwide study and found that mental illness-related stigma and discrimination are widespread among countries in Asia. An internet-based study in Japan revealed that people's professional groups were stigmatised towards mental illness compared to the general population ${ }^{10}$. At the community level, the family members had a lower stigma to the general population ${ }^{11}$. People in the community who suffered from mental illness were 
not seeking treatment due to fear of being stigmatised by their community ${ }^{12}$.

Several factors were found to be affecting factors to mental health-related stigma. Female respondents are more stigmatised towards mental illness than male respondents ${ }^{13}$. However, the findings contradicted Razali and Ismail ${ }^{11}$, revealing that male respondents displayed a more social distance towards mental illness patients. Furthermore, a few studies found that people with higher education levels are more likely to have lower levels of stigma and discrimination towards mental illness ${ }^{11,14-16}$. However, contradictory findings show that people with higher education levels have a higher stigma towards the mentally ill ${ }^{13,17}$.

There were limited studies to examine the stigma and discrimination towards mental illness among the community in rural areas of Sarawak, Malaysia. The uniqueness of rural communities is that when they experienced someone among their family members who developed symptoms of mental problems, they stay at their place or seek treatment from shamans or witchcraft practitioners. This is most probably due to the stigma against mental illness and do not want to be discriminated against. There is an inadequate exploration of the effect of education on stigma and discrimination toward mental illness. Therefore, this study is essential to fill in the research gap. This study's main objective was to determine the stigma and discrimination toward mental illness among Sarawak's rural community and the affecting factors. The findings could be applied in designing effective programs that would combat public stigma towards mental illness and provide guidance for the local authorities or government to undertake further strategic action.

\section{METHODS}

Study population and sampling procedure

This was a cross-sectional study using a multistage sampling method to recruit the respondents from the rural areas of Sarawak, Malaysia. Sarawak is located in East Malaysia, also known as Malaysia Borneo Island. Random selection was done to choose three divisions and subsequently two districts from each division. Then, five rural villages and 28 households were selected by systematic random sampling technique. Malaysian citizens aged 21 years and above with no mental illness or drug dependence and residing in rural areas were included in this study. Those who were unable to answer the questionnaire or refused to sign the consent form were excluded from the study. The sample size was calculated using the population proportion formula. With the anticipation of a $10 \%$ non-response rate, there were 840 respondents included in this study.

\section{Data collection instrument}

Data were collected using an intervieweradministered questionnaire which includes demographic characteristics. The others were adapted from different sources such as stigma ${ }^{18}$, discrimination ${ }^{13}$, knowledge ${ }^{14,16}$, media influence ${ }^{16}$ and previous experience with mentally ill ${ }^{16}$. Two translators have translated the questionnaire items forward and backward between Malay and English language. The experts reviewed the Malay version, and minor changes were made based on their feedback. Finally, the Malay version questionnaire was pretested among 30 respondents from a non-sampled area.

\section{Stigma towards mental illness}

Stigma towards mental illness questionnaire was adapted from the Community Attitudes towards Mental Illness (CAMI) scale ${ }^{18}$. This questionnaire has four domains: authoritarianism, benevolence, social restrictiveness, and community ideology towards mental health, with ten items for each domain. Respondents were required to rate each item from 1 to 5 (Likert's scale), defining strongly disagree to strongly agree. Cronbach's alpha of .60 and above was attained.

\section{Discrimination towards mental illness}

There was 13-items for the discrimination assessment. Like the stigma questionnaire, respondents were also required to rate each item according to the Likert scale of 1 to 5 , strongly disagreed to strongly agree. Cronbach alpha for discrimination towards people with mental illness was 0.782 .

\section{Knowledge of mental illness}

This variable had 11 items, and respondents were required to answer each item with either a 'Yes', 'No', or 'Do not know'. Based on the correct responses, a summative score was calculated.

\section{Media influence on mental illness}

The media influence questionnaire consisted of seven items and required the respondents to answer a 'yes' or 'no' for each item. The answer 'yes' for unwanted media influence item and 'no' for the right media influence item would attain a score of 1 . Otherwise, a score of zero was given.

\section{Experience with people with mental illness}

Six questions with four positive and two negative question items were used to assess the experience with the mentally ill patient. Each positive item was scored 1 for 'yes' and zero for 'no'. Meanwhile, it was scored 1 for 'no' and zero for 'yes' for each negative item.

\section{Ethical issues}

The research assistants were briefed on the study and the objectives, which they later explain to the respondents. Respondents were also informed that their contribution was voluntary and asked to sign a written consent before data collection. The data received from the respondents were kept 
anonymous and kept strictly confidential. Before conducting the research, ethics approval was obtained from authorities.

\section{Data analysis}

Microsoft Excel with a validation check was used for data entry to ensure correct data entry. IBM SPSS was used for data analysis ${ }^{19}$. Descriptive statistics were presented with means, standard deviations, percentages, and frequency. Inferential statistics were applied to test the associations of each dependent variable and independent variable. The standardised stigma and discrimination scores were calculated and became dependent variables. We hypothesised that gender and education level might influence stigma and discrimination towards mentally ill patients. However, age and experience with mentally ill patients had a linear effect on stigma and discrimination towards ill patients, considered covariate. A two-way analysis of covariance (MANCOVA) was carried out to reduce type 1 error and quantified the influencing factors. Box's Test of Equality of Covariance Matrices was tested to assume homogeneity of covariance across groups. Wilk's Lambda results were interpreted, showing the statistical significance of the differences between groups. Mahalanobis distance was determined to test for multivariate outlier ${ }^{20}$. A p-value of less than .05 was considered statistically significant.

\section{RESULTS}

\section{Participant characteristics}

A total of 840 data with equal distribution of male and female was analysed. The mean (SD) age of respondents was $43.02(11.14)$ years. Table 1 illustrates the respondents' characteristics. Malay, Muslim and living with a partner make up the majority of the participants. The result shows that the highest education level was secondary education $(50.1 \%)$, followed by primary education (30.5\%). Most of the respondents were unemployed $(45.5 \%)$, followed by self-employed (35.8\%), with the mean monthly household income was MYR1012.24 (Table 1).

\section{Experience with mentally ill}

Table 2 illustrates the experience with mentally ill patients. The mean (SD) for total experience with a mentally ill patient score was 2.85 (1.16). Most respondents had no comfortable experience when they were chased by mentally ill patients (95.1\%) or disturbed by them $(84.3 \%)$.

\section{Stigma and discrimination towards mental illness}

Table 3 demonstrates the standardised stigma and discrimination score by gender and level of education. With regards to the standardised stigma score, analysis showed that the highest standardised stigma mean (SD) for male respondents were among those with no formal education, 0.352 (1.141). A similar result was seen among female respondents with no formal education where, the highest standardised stigma mean (SD) was $0.586(0.983)$. These standardised stigma scores for both male and female respondents showed a decrement when increasing the level of education. Furthermore, the standardised discrimination scores also decrease when increasing the level of education among male and female respondents. The highest standardised discrimination mean (SD) for male respondent was $0.253(1.107)$, where 0.110 (1.141) for female respondent where both have no formal education.

\section{Factors influencing stigma and discrimination towards mental illness}

To test our research question, how much the gender and level of education influence stigma and discrimination towards mentally ill patients, a two-way multivariate analysis of covariance (MANCOVA) was carried out. The dependent variables were the standardised stigma and discrimination score. The independent variables were gender and education level, whereas age and experience were included in the model as covariates.

Two-way MANCOVA revealed that there was a statistically significant difference of standardised stigma and discrimination scores among different levels of education, $(F(6,1658)=4.217, p<.001$, Wilks' Lambda $=.970$, partial eta squared $=.015$ ). However, there was no statistically significant difference of standardised stigma and discrimination scores based on gender $(F(2,829)=$ $0.489, p=.614$, Wilks' Lambda $=.999$, partial eta squared $=0.001)$. Test of between-subjects effects demonstrated that there was a statistically significant difference of standardised stigma score among different levels of education $(F(3,830)=7.423, p<.001$, partial eta squared $=0.026)$. Furthermore, the results showed no statistically significant difference in standardised discrimination scores among different education levels $(F(3,830)=0.846, p=.469$, partial eta squared $=.003)$.

The post-doc comparison of Bonferroni test found that there was a statistically significant mean difference of standardised stigma score $(p<.05)$ between respondent with tertiary education (mean $=-0.49, \mathrm{SD}=0.84)$ and respondent with other level of education; no formal education (mean $=0.47, \mathrm{SD}=1.07)$, primary education (mean $=0.20, S D=1.02$ ) and secondary education (mean $=-0.11, \mathrm{SD}=0.94)$. Besides, there was $\mathrm{a}$ statistically significant mean difference of standardised stigma score $(p<.05)$ between respondents with secondary education and respondent with no formal education. 
Table 1 Characteristics of the respondents

\begin{tabular}{|c|c|c|c|}
\hline Characteristics & Frequency & Percentage (\%) & Statistics \\
\hline \multicolumn{4}{|l|}{ Age in years } \\
\hline$<30$ & 112 & 13.3 & Mean $(S D)=43.02(11.14)$ \\
\hline $30-39$ & 229 & 27.3 & years \\
\hline $40-49$ & 228 & 27.1 & Min, 21; Max, 78 \\
\hline $50-59$ & 228 & 27.1 & \\
\hline$\geq 60$ & 43 & 5.1 & \\
\hline \multicolumn{4}{|l|}{ Ethnicity } \\
\hline Malay & 271 & 32.3 & \\
\hline Iban & 267 & 31.8 & \\
\hline Bidayuh & 120 & 14.3 & \\
\hline Melanau & 74 & 8.8 & \\
\hline Others $^{\mathrm{a}}$ & 108 & 12.9 & \\
\hline \multicolumn{4}{|l|}{ Religion } \\
\hline Islam & 377 & 44.9 & \\
\hline Christian & 376 & 44.8 & \\
\hline Others ${ }^{\mathrm{b}}$ & 87 & 10.4 & \\
\hline \multicolumn{4}{|l|}{ Living status } \\
\hline Living with partner & 654 & 77.9 & \\
\hline Living without partner & 186 & 22.1 & \\
\hline \multicolumn{4}{|l|}{ Level of education } \\
\hline No formal education & 78 & 9.3 & \\
\hline Primary education & 256 & 30.5 & \\
\hline Secondary education & 421 & 50.1 & \\
\hline Tertiary education & 85 & 10.1 & \\
\hline \multicolumn{4}{|l|}{ Occupation } \\
\hline Unemployed & 382 & 45.5 & \\
\hline Private & 82 & 9.8 & \\
\hline Government & 49 & 5.8 & \\
\hline Self-employed & 301 & 35.8 & \\
\hline Retiree & 26 & 3.1 & \\
\hline \multicolumn{4}{|l|}{ Monthly income (MYR) } \\
\hline$<501$ & 142 & 16.9 & Mean $(S D)=1012.24$ \\
\hline 501 to 1000 & 468 & 55.7 & $(627.01)$ \\
\hline 1001 to 1500 & 126 & 15.0 & Min, 200; Max, 7000 \\
\hline$>1500$ & 104 & 12.4 & \\
\hline
\end{tabular}

athers included Chinese, Orang Ulu, b'Others included Buddhism, Hinduism, no religion

Table 2 Distribution of experience with mentally ill

\begin{tabular}{lcc}
\hline Experience with a mentally ill patient & Yes & No \\
\hline I have previous experience taking care of a family member & 8.9 & 91.1 \\
that is mentally ill & & 82.4 \\
I have a family member that is mentally ill & 17.6 & 51.4 \\
I have communicated with people who have a mental illness & 48.6 & 69.0 \\
I have lived beside people with mental illness & 31.0 & 84.3 \\
I have been disturbed by a mentally ill patient (-) & 15.7 & 95.1 \\
I have been chased by a mentally ill patient (-) & 4.9 & \multicolumn{2}{c}{$2.85(1.16)$} \\
\hline Mean (SD) & \multicolumn{2}{c}{0,6} \\
Min, Max & \multicolumn{2}{c}{} \\
\hline
\end{tabular}


Malaysian Journal of Public Health Medicine 2021, Vol. 21 (2): 329-337

Table 3 Standardised stigma and discrimination score by gender and level of education

\begin{tabular}{|c|c|c|c|c|}
\hline & Gender & Level of education & Mean & SD \\
\hline \multirow[t]{8}{*}{ Standardised Stigma score } & \multirow[t]{4}{*}{ Male } & No formal education & 0.352 & 1.141 \\
\hline & & Primary education & 0.187 & 1.031 \\
\hline & & Secondary education & -0.110 & 0.946 \\
\hline & & Tertiary education & -0.488 & 0.713 \\
\hline & \multirow[t]{4}{*}{ Female } & No formal education & 0.586 & 0.983 \\
\hline & & Primary education & 0.210 & 1.009 \\
\hline & & Secondary education & -0.105 & 0.942 \\
\hline & & Tertiary education & -0.492 & 0.950 \\
\hline \multirow[t]{8}{*}{ Standardised discrimination score } & \multirow[t]{4}{*}{ Male } & No formal education & 0.253 & 1.107 \\
\hline & & Primary education & 0.134 & 0.949 \\
\hline & & Secondary education & -0.075 & 1.019 \\
\hline & & Tertiary education & -0.370 & 0.848 \\
\hline & \multirow[t]{4}{*}{ Female } & No formal education & 0.110 & 1.141 \\
\hline & & Primary education & 0.105 & 0.998 \\
\hline & & Secondary education & -0.046 & 0.963 \\
\hline & & Tertiary education & -0.124 & 1.059 \\
\hline
\end{tabular}

Table 4 illustrates the results of two-way multivariate analysis of covariance (MANCOVA) for community stigma and discrimination towards mental illness and the linear effect of covariates (age in years and experience) to each dependent variable. The analysis showed no statistically significant difference in stigma and discrimination towards mental illness and gender $(p>.05)$. However, there were statistically significant difference of stigma and level of education; included no formal education $(B=0.789, p<.001)$, primary education $(B=0.561, \quad \mathrm{p}<.01)$, and secondary education $(B=0.335$, $\mathrm{p}<.05)$. Age had a significant positive linear effect on standardised stigma towards mental illness ( $B$ $=0.012, \mathrm{p}<.01)$. In contrast, experience negatively affected mental illness stigma $(B=$ $0.144, p<.001)$. Furthermore, the analysis also found that education level had no significant influence on discrimination towards mental illness. However, age in years had a positive linear effect on standardised discrimination $(B=0.012$, $\mathrm{p}<.01)$, whereas experience had a negative linear effect on standardised discrimination $(B=-0.124$, $\mathrm{p}<.001)$.

Table 4 Factors influencing stigma and discrimination towards mental illness: Multivariate Analysis of Covariance

\begin{tabular}{|c|c|c|c|c|}
\hline \multirow{2}{*}{ Parameter } & \multirow{2}{*}{ B } & \multirow{2}{*}{ SE } & \multicolumn{2}{|c|}{$95 \% \mathrm{Cl}$} \\
\hline & & & LL & UL \\
\hline \multicolumn{5}{|l|}{ Standardised stigma } \\
\hline Intercept & $-.470^{*}$ & .198 & -.857 & -.082 \\
\hline \multicolumn{5}{|l|}{ Gender } \\
\hline Male & -.024 & .208 & -.432 & .385 \\
\hline Female (RC) & 0.0 & & & \\
\hline \multicolumn{5}{|l|}{ Level of education } \\
\hline No formal education & $.789^{* * *}$ & .222 & .353 & 1.225 \\
\hline Primary education & $.561^{* *}$ & .173 & .222 & .900 \\
\hline Secondary education & $.335^{*}$ & .155 & .030 & .640 \\
\hline Tertiary education (RC) & 0.0 & & & \\
\hline Age in years & $.012^{* *}$ & .004 & .005 & .019 \\
\hline Experience score & $-.144^{* * *}$ & .029 & -.200 & -.088 \\
\hline \multicolumn{5}{|l|}{ Standardised discrimination } \\
\hline Intercept & -.162 & .203 & -.561 & .237 \\
\hline \multicolumn{5}{|l|}{ Gender } \\
\hline Male & -.278 & .214 & -.698 & .142 \\
\hline Female (RC) & 0.0 & & & \\
\hline \multicolumn{5}{|l|}{ Level of education } \\
\hline No formal education & -.054 & .229 & -.502 & .395 \\
\hline Primary education & .085 & .178 & -.264 & .434 \\
\hline Secondary education & .023 & .160 & -.291 & .336 \\
\hline Tertiary education (RC) & 0.0 & & & \\
\hline Age in years & $.012^{* *}$ & .004 & .005 & .019 \\
\hline Experience score & $-.124^{* * *}$ & .029 & -.182 & -.067 \\
\hline
\end{tabular}

${ }^{*} p<.05,{ }^{* *} p<.01,{ }^{* * *} p<.001$

$R C$ : Reference category, $L L=$ Lower limit of $95 \% \mathrm{Cl}, \mathrm{UL}=$ Upper limit of $95 \% \mathrm{Cl}$

$\mathrm{Cl}=$ Confidence interval 


\section{DISCUSSION}

There are minimal studies that examined both stigma and discrimination toward mental illness at the same time. This study identified the factors influencing stigma and discrimination towards mental illness. The final model revealed that gender was not an influencing factor for stigma and discrimination. The finding showed that the level of education was an influencing factor for stigma but not for discrimination. Furthermore, a decrease in age and an increase in experience led to significant improvement in stigmatisation and discrimination towards mental illness.

Previous studies had shown that gender is one of the predictors of stigma ${ }^{21,22}$ and discrimination 13,14 towards mental illness. However, this relationship was not found in this study. In other studies, Bedaso et al. ${ }^{21}$ and Poreddi et al..23 revealed that females were more stigmatised than males. This contradicts Pascucci et al. ${ }^{22}$ in Italy, which demonstrated that females are less stigmatised towards mental illness than males. In terms of discrimination, Li et al. ${ }^{24}$ revealed that gender did not affect discrimination. Meanwhile, Chan et al. ${ }^{13}$ found that female respondents discriminate against people with mental illness, which contradicted Evans-Lacko et al. ${ }^{14}$.

The level of education highly influenced stigma towards mental illness but not discrimination in this study. Respondents with a higher level of education tend to have a lesser stigma. In other words, mentally ill patients were more accepted among more educated people in the community. The possible reason might be that people with higher education might gain more mental illness information, leading to a deeper understanding of this illness and lesser stigma. However, the finding contradicted Reta et al. ${ }^{17}$ and Bedaso et al. ${ }^{21}$, which found that higher educated people had higher social restrictiveness views on people with mental illness.

Age was found to have a positive linear effect on stigma and discrimination toward mental illness in this study, which means people with an increase in age would have greater stigma and discrimination. This might be because older people gained more trouble dealing with mental illness people and tend to discriminate. However, this finding was not consistent with $\mathrm{Li}$ et al. ${ }^{24}$ in China and Hsiao et al. ${ }^{25}$ in Taiwan. Moreover, Chan et $\mathrm{al}^{13}$ and Toner et al. ${ }^{26}$ demonstrated that age did not significantly discriminate mental illness. Other studies also found that age did not affect the stigmatised attitude ${ }^{17,21,23}$.

This study also revealed that greater experience with the mentally ill patient would lead to lesser stigma and mental illness discrimination. People with experience logically will gain understanding and acceptance of the mentally ill patient. However, this finding is not consistent with Reta et al. ${ }^{17}$, which showed that people with less experience with mentally ill patients were less discriminated. Previous studies also did not show any relationship between experience and discrimination towards mentally ill patients ${ }^{26,27}$.

There are some limitations to this study. Firstly, the cross-sectional nature of the data, which is not a causal relationship of the findings. The associations found from the analysis support the hypothesis that education, age and experience affect the stigma and discrimination toward mental illness. Secondly, since the information collected used a self-report method, there might be some respondents' information bias. Although the finding can be generalised to the general population, the non-respondents may have different influencing factors to stigma and discrimination toward mental illness.

\section{CONCLUSION}

From this study, level of education was a significant predictor, with less-educated respondents being more stigmatised and discriminated toward the mentally ill patients. Furthermore, age and experience also affected stigma and discrimination towards mental illness. Future research using alternative methods might obtain a more accurate finding of stigma and discrimination toward mentally ill patients and their influencing factors. Efforts to challenge this stigma and discrimination through targeted antistigma campaigns and public education are essential. Nevertheless, the study findings here would be useful to guide further studies and general actions before it could be applied in designing effective programs to undertake further strategic actions.

\section{Conflict of interest}

The authors declare no potential conflict of interest.

\section{Acknowledgements}

We would like to thank all the participants in this study. We are grateful to National Medical Research Register (NMRR), Ministry of Health, Malaysia [NMRR-19-2516-49950] and Medical Ethics Committee of Universiti Malaysia Sarawak [UNIMAS/NC-21.02/03-02 Jld.2 (08)] for the approval of this study. We are also grateful UNIMAS for support to conduct this research.

\section{Funding}

The authors received no fund for this study.

Permission for publication

This publication was consented to by all authors.

\section{REFERENCES}

1. GBD 2016 Causes of Death Collaborators. Global, regional, and national age-sex specific mortality for 264 causes of death, 
1980-2016: a systematic analysis for the Global Burden of Disease Study 2016. Lancet Lond Engl. 2017;390(10100):11511210. doi:10.1016/S0140-6736(17)321529

2. GBD 2016 Mortality Collaborators. Global, regional, and national under-5 mortality, adult mortality, age-specific mortality, and life expectancy, 1970-2016: a systematic analysis for the Global Burden of Disease Study 2016. Lancet Lond Engl. 2017;390(10100):1084-1150.

doi:10.1016/S0140-6736(17)31833-0

3. Rehm J, Shield KD. Global Burden of Disease and the Impact of Mental and Addictive Disorders. Curr Psychiatry Rep. 2019;21(2):10. doi:10.1007/s11920-0190997-0

4. Liu Q, He H, Yang J, Feng X, Zhao F, Lyu J. Changes in the global burden of depression from 1990 to 2017: Findings from the Global Burden of Disease study. $J$ Psychiatr Res. 2020;126:134-140. doi:10.1016/j.jpsychires.2019.08.002

5. Ministry of Health, Malaysia. National Health Morbidity Survey 2015 (NHMS 2015). Vol. II: Non-Communicable Disease, Risk Factors \& Other Health Problems. National Institutes of Health; 2016.

http://iku.moh.gov.my/images/IKU/Doc ument/REPORT/nhmsreport2015vol2.pdf

6. Ministry of Health, Malaysia. National Health and Morbidity Survey (NHMS) 2019: Vol. I: NCDs - Non-Communicable Diseases: Risk Factors and Other Health Problems. National Institutes of Health; 2020:392.

http://www.iku.gov.my/images/IKU/Doc ument/REPORT/NHMS2019/Report_NHMS 2019-NCD_v2.pdf

7. $\mathrm{Ng}$ CG. A Review of Depression Research in Malaysia. Med J Malaysia. 2014;69 Suppl A:42-45.

8. Schomerus G, Stolzenburg S, Freitag S, et al. Stigma as a barrier to recognizing personal mental illness and seeking help: a prospective study among untreated persons with mental illness. Eur Arch Psychiatry Clin Neurosci.2019; 269(4):469-479.doi:10.1007/s00406-0180896-0

9. Seeman N, Tang S, Brown AD, Ing A. World survey of mental illness stigma. J Affect
Disord. 2016;190:115-121. doi:10.1016/j.jad.2015.10.011

10. Fujii T, Hanya M, Kishi M, Kondo $Y$, Cates ME, Kamei $\mathrm{H}$. An internet-based survey in Japan concerning social distance and stigmatization toward the mentally ill among doctors, nurses, pharmacists, and the general public. Asian J Psychiatry. 2018;36:1-7.

doi:10.1016/j.ajp.2018.05.017

11. Razali SM, Ismail Z. Public stigma towards patients with schizophrenia of ethnic Malay: a comparison between the general public and patients' relatives. J Ment Health. 2014;23(4):176-180. doi:10.3109/09638237.2014.910644

12. Bartolomei J, Baeriswyl-Cottin R, Framorando $\mathrm{D}$, et al. What are the barriers to access to mental healthcare and the primary needs of asylum seekers? A survey of mental health caregivers and primary care workers. BMC Psychiatry. 2016;16(1):336. doi:10.1186/s12888-0161048-6

13. Chan SKW, Tam WWY, Lee KW, et al. A population study of public stigma about psychosis and its contributing factors among Chinese population in Hong Kong. Int J Soc Psychiatry. 2016;62(3):205-213. doi:10.1177/0020764015621941

14. Evans-Lacko S, Henderson C, Thornicroft G. Public knowledge, attitudes and behaviour regarding people with mental illness in England 2009-2012. Br J Psychiatry. $\quad 2013 ; 202(s 55): s 51-s 57$. doi:10.1192/bjp.bp.112.112979

15. Noh J-W, Woo J-M, Park H, Jung SJ, Lee Y, Kwon YD. Factors Related to the Attitude of North Korean Refugees Towards People with Mental Illness. Iran J Public Health. 2018;47(Suppl 1):39-46.

16. Siti Zubaidah S, Norfazilah A. Attitudes towards the mentally ill patients among a community in Tampoi, Johor, Malaysia, 2012 to 2013. Malays J Public Health Med. 2014;14(3):1-7.

17. Reta Y, Tesfaye M, Girma E, Dehning S, Adorjan K. Public Stigma against People with Mental Illness in Jimma Town, Southwest Ethiopia. PLOS ONE. 2016;11(11): e0163103. doi:10.1371/journal.pone.0163103 
18. Taylor SM, Dear MJ. Scaling community attitudes toward the mentally ill. Schizophr Bull. 1981;7(2):225-240.

19. IBM SPSS. IBM SPSS Statistics Software Version 22. Published online 2014.

20. Tabachnick B, Fidell L. Using Multivariate Statistics. 6th Edition. Pearson Education, Inc; 2013.

21. Bedaso A, Yeneabat $T$, Yohannis $Z$, Bedasso K, Feyera F. Community Attitude and Associated Factors towards People with Mental Illness among Residents of Worabe Town, Silte Zone, Southern Nation's Nationalities and People's Region, Ethiopia. Dalal K, ed. PLOS ONE. 2016;11(3):e0149429.

doi:10.1371/journal.pone.0149429

22. Pascucci M, Montagna ML, Sabatino DD, et al. Stigma and attitudes towards mental illness: Gender differences in a sample of Italian medical students. Eur Psychiatry. 2017;41(S1):S739-S739.

doi:10.1016/j.eurpsy.2017.01.1359

23. Poreddi V, Thimmaiah $\mathrm{R}$, Math SB. Attitudes toward people with mental illness among medical students. J Neurosci Rural Pract. 2015;6(3):349-354. doi:10.4103/0976-3147.154564
24. Li J, Zhang M, Zhao L, Li W, Mu J, Zhang $Z$. Evaluation of attitudes and knowledge toward mental disorders in a sample of the Chinese population using a web-based approach. BMC Psychiatry. 2018;18(1):367. doi:10.1186/s12888-0181949-7

25. Hsiao C-Y, Lu H-L, Tsai Y-F. Factors influencing mental health nurses' attitudes towards people with mental illness. Int J Ment Health Nurs. 2015;24(3):272-280.

doi:10.1111/inm.12129

26. Toner S, Fabisch K, Priebe S, Klug G. Attitudes towards severe mental illness and social distance: A survey of volunteer befrienders in Austria. Int $J$ Soc Psychiatry. 2018;64(5):470-475. doi: $10.1177 / 0020764018776346$

27. Abi Doumit C, Haddad C, Sacre H, et al. Knowledge, attitude and behaviors towards patients with mental illness: Results from a national Lebanese study. PLOS ONE. 2019;14(9):e0222172. doi:10.1371/journal.pone.0222172 